\title{
SPATIOTEMPORAL ANALYSIS OF VEGETATION DROUGHT VARIABILITY IN THE MIDDLE OF THE NORTHEAST REGION OF THAILAND USING TERRA/MODIS SATELLITE DATA
}

\author{
Nanthawat JOMSREKRAYOM ${ }^{1}$, Pattanapol MEENA 2 (D), Teerawong LAOSUWAN ${ }^{3}$ (iD)
}

DOI: 10.21163/GT_2021.163.06

\begin{abstract}
:
Drought is one of Thailand's most common catastrophes and causes a considerable amount of damage, especially to farming, in the northeast of the country. The objective of this study is to analyze vegetation drought variability from a vegetation phenology perspective using the vegetation condition index (VCI) from Terra/MODIS satellite data in the middle of the northeast region of Thailand .The MOD09A1 dataset from Terra/MODIS satellites was analyzed using the normalized difference vegetation index (NDVI), and the results were analyzed with the VCI to examine vegetation drought variability in July, August, and September 2009-2019. The study found that in August 2013, the drought was most severe and accounted for $47.71 \%$ coverage $\left(22,456.76 \mathrm{~km}^{2}\right)$, and in September 2013, the drought was the least severe at $55.55 \%$ coverage $\left(17,456.42 \mathrm{~km}^{2}\right)$ Moreover, using simple linear regression analysis, the VCI results for each month of the 11-year period were used to find the statistical correlation with rainfall data from ground monitoring stations. It found that July, August, and September showed a coefficient of determination $\left(\mathrm{r}^{2}\right)$ equal to $0.835,0.834$, and 0.849 , respectively. The $\mathrm{r}^{2}$ value showed that this method was reliable. Furthermore, the analyzed VCI averages can be used as a very good indicator of drought in the middle of the northeast region of Thailand.
\end{abstract}

Key-words: Remote sensing, Vegetation drought variability, NDVI, VCI

\section{INTRODUCTION}

Drought is a natural disaster that occurs in many areas and is a devastating and detrimental problem for national development. Areas that experience drought often also experience water shortages for consumption and agriculture. Thai farming relies mainly on natural rainwater, and when there is insufficient water, the crop yield decreases, which, in turn, causes a shortage of agricultural and process products for domestic consumption and exports (Laosuwan et al., 2016 ). Drought has a direct impact on the economy and an indirect impact on society and culture, which has resulted in the abandonment of agriculture and people migrating to work in the city when normal farming is not possible.Additionally, extremely dry conditions can also cause forest fires, which is another environmental problem (Uttaruk \& Laosuwan, 2017). The development of drought is a gradual process, the severity of which is constantly increasing. This makes the process difficult to understand. Drought conditions are generally estimated by decreasing rainfall, resulting in water shortages for some activities (Malo \& Nicholson, 1990). To accurately determine drought is challenging because it is a natural disaster that progresses slowly. Drought has different intensities due to rainfall imbalances in a particular area, which makes it difficult to make comparisons at any one time, as one area may be drier than another (Rotjanakusol \& Laosuwan, 2018). Nevertheless, weather data, especially rainfall data, can be considered the most widely used primary information for drought tracking . However, there are relatively few weather station networks in the northeastern region of Thailand; therefore, weather data is often incomplete, and the weather data logging model is not usually readily

${ }^{1,2,3}$ Department of Physics, Faculty of Science, Mahasarakham University, Maha Sarakham, 44150, Thailand bomnantawat1995@gmail.com, pattanapol.m@msu.ac.th, "Corresponding authorteerawong@msu.ac.th 
available for immediate analysis; thus, monitoring drought and assessing the influence of weather conditions on farmland is sometimes unreliable (Gebrehiwot et al., 2011; Lines et al., 2017).

The application of satellite-based remote sensing technology to monitor periods of unusually dry conditions is another method quickly detect droughts because satellite data is re-recorded continuously, so it can be used to monitor the area in near real-time over different periods (Kogan, 1997; Gu et al., 2007; Zhang et al., 2013; Rotjanakusol \& Laosuwan, 2019a; Rotjanakusol \& Laosuwan, 2019b). To use satellite data to estimate drought, derivative data from earth-observing satellites are often analyzed as they can reflect the drought conditions of the area. This is because the different biological characteristics of vegetation cover are related to the spatial and temporal patterns of drought as the plants respond to dehydration, such as withering and leaf drop; this occurs because Thailand is in a region with distinct wet and dry seasons (Uttaruk \& Laosuwan, 2019).

Although satellite data suggest that changes in vegetation in arid regions appear to have different reflectance values, studies have found that the data may need to be adjusted so that it is fit for the research purpose or enhanced to make the topic of study clearer, which is referred to as indexing (Tucker, 1979). As drought is such a complex phenomenon, it is difficult to use just one index to cover studies in terms of quantity, density, and severity as well as the possibility of their impact on each group (Fensham \& Holman, 1999). Therefore, a drought study with remote sensing technology has applied wave indices related to the physical conditions of vegetation, plant water content, and soil water content to examine and study drought with multiple indices, such as the NDVI (Tarpley et al., 1984), the soil-adjusted vegetation index (SAVI; Huete, 1988), the vegetation condition index (VCI; Kogan, 1995), the normalized difference water index (NDWI; Gao, 1996), the enhanced vegetation index (EVI; Huete et al., 2002), and the standardized vegetation index (SVI; Peters et al., 2002). For this reason, the objective of this study is to analyze vegetation drought variability from a vegetation phenology perspective using vegetation condition index - VCI from Terra/MODIS satellite data in the middle of the northeast region in July, August, and September 2009-2019.

\section{MATERIALS AND METHODS}

The middle of the northeast region of Thailand (Fig. 1) is located between latitude $17-25^{\circ} \mathrm{N}$ and longitude $101-103^{\circ}$ E, covering the provinces of Kalasin, Khon Kaen, Maha Sarakham, and Roi Et.

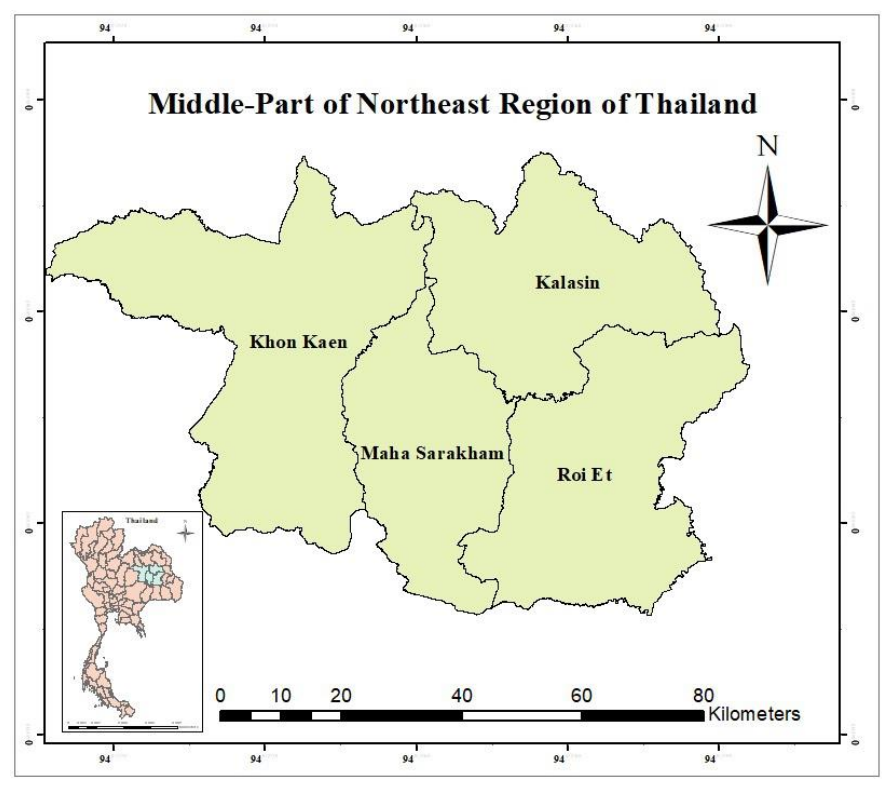

Fig.1. Study area. 
The total area of the provincial clusters is $31,423.87 \mathrm{~km}^{2}$, accounting for $6.18 \%$ of the total country area and $18.61 \%$ of the northeastern region. Agricultural areas equal $21,736.708 \mathrm{~km}^{2}$ or $69.17 \%$ of the province's area; Khon Kaen is the largest area, followed by Roi Et Province, Kalasin Province, and Maha Sarakham Province, respectively. The overall topography is lowland and is approximately 200 meters above sea level. Climate characteristics are classified as rain alternating with drought. The average maximum temperature is $36.35^{\circ} \mathrm{C}$, and there are three seasons: summer, rainy, and winter.

\subsection{Terra/MODIS data}

Terra/MODIS is designed to track and monitor natural resources. It is approximately $2,330 \mathrm{~km}$ wide with a spatial resolution ranging from 250 to $1000 \mathrm{~m}$ and 36 wavelength data logging, which covers the entire globe in two days. Therefore, data from Terra/MODIS satellites are ideal for tracking spatial changes. In this operation, the MOD09A1 product suite was used to collect data from satellites between July and September 2009-2019 at h27v07 and h28v07. In this study, Mosaic Image was used to concatenate the two datasets to cover the entire study area. Then, the geometric correction was adjusted using the WGS84-UTM zone $47 \mathrm{~N}$ reference coordinate system by evaluating the pixels using the nearest neighbor method.

\subsection{Rainfall data}

This study was based on the average monthly rainfall data from July to September 2009-2019 from the Thailand Meteorological Department's terrestrial rainfall monitoring station.

\subsection{Procedures for analysis}

Multi-period data from Terra/MODIS satellites was applied to the VCI to examine the vegetative drought in the middle of the northeast region of Thailand.

\subsubsection{NDVI analysis}

The VCI uses a value to indicate the proportion of vegetation covering the earth's surface and can be calculated by the proportion of related wavelengths of vegetation to each other. A popular method is the NDVI (Prohmdirek et al., 2020), which is a surface reflectance measure that provides quantitative estimates of plant growth and biomass (Jingyong et al., 2003; Pettorelli et al., 2005). The difference in surface reflection between the near-infrared (NIR) wavelength and red wavelength is proportional to the sum of the two wavelengths to adjust the normal distribution characteristics can be adjusted. This results in an NDVI between -1 and +1 , which will help translate the results more easily. A value of 0 means that there are no green leafy plants in the survey area, while a value of 0.8 or 0.9 suggests very dense green vegetation in the area.

In the case of vegetation-covered surfaces, the reflectance in the NIR wavelength is higher than the red wavelength, making the NDVI positive, while the terrestrial surface has a similar reflection between the two wavelengths, so the NDVI value is close to 0 . If the water surface has a reflection in the NIR wavelength below the red wavelength, the NDVI is negative. Usually, this value only ranges from 0.1 to 0.7 . Equation 1 calculates the vegetation values for NDVI (Peters et al., 2002):

$$
\mathrm{NDVI}=\frac{\mathrm{NIR}-\mathrm{RED}}{\mathrm{NIR}+\mathrm{RED}}
$$

where

NIR = reflection in the NIR wavelength of the spectrum

RED =reflection in the red wavelength of the spectrum

2.3.2. VCI analysis 
The VCI is an index derived from remote sensing data. It compares the current NDVI with a range of values observed for the same period in the previous year. Droughts mostly affect the agricultural sector; therefore, plant growth and conditions are affected. VCI is an alternative to looking at vegetation conditions and characterizing agricultural drought. The principle of the VCI is a standard range analysis that determines the state of the NDVI at the current time of interest where it is positioned in the lowest and highest NDVI ranges for a particular area. The equation and table showing the plant values of VCI are shown in Equation 2 and Table 1 (Kogan, 1995; Quiring et al., 2010):

$$
\mathrm{VCI}=\frac{\mathrm{NDVI}^{-N D V I} I_{\text {min }}}{\mathrm{NDVI}_{\text {max }}-\mathrm{NDVI}_{\text {min }}} \times 100
$$

where

$\mathrm{NDVI}_{\max }=$ maximum NDVI at the study time of each pixel

$\mathrm{NDVI}_{\min }=$ minimum NDVI at the study time of each pixel

\section{VCI drought levels.}

\begin{tabular}{cc}
\hline Level & VCI \\
\hline $00.00-20.00$ & very high drought \\
$21.00-40.00$ & high drought \\
$41.00-60.00$ & moderate drought \\
$61.00-80.00$ & low drought \\
$81.00-100.00$ & very low drought \\
\hline
\end{tabular}

\subsection{Statistical correlation analysis}

In this study, VCI results and average monthly rainfall data for July to September 2009-2019 were taken from the ground rain measurement station of the Thai Meteorological Department to find statistical relationships in the form of linear regression analysis.

where

$$
\mathrm{y}=\mathrm{ax}+\mathrm{b}
$$

$\mathrm{x}=$ independent variable

$\mathrm{y}=$ dependent variable

\section{RESULTS AND DISCUSSION}

\subsection{NDVI analysis results}

The monthly NDVI analysis in July showed an average of 0.47 , with the lowest of 0.42 in 2019 , and the highest of 0.53 in 2018. In August, the mean was 0.54, with the lowest of 0.44 in 2013, and the highest of 0.60 in 2014; in September, the mean was 0.63 , with the lowest of 0.43 in 2011, and the highest of 0.70 in 2016. The results of the NDVI analysis that were mean for the three months across 11 years is shown in Fig. 2, with the curves showing the variance of NDVI for each year; the lowest value of 0.47 occurred in 2011, the highest value of 0.60 occurred in 2016, and the 11-year average was 0.55 (Fig. 3). 


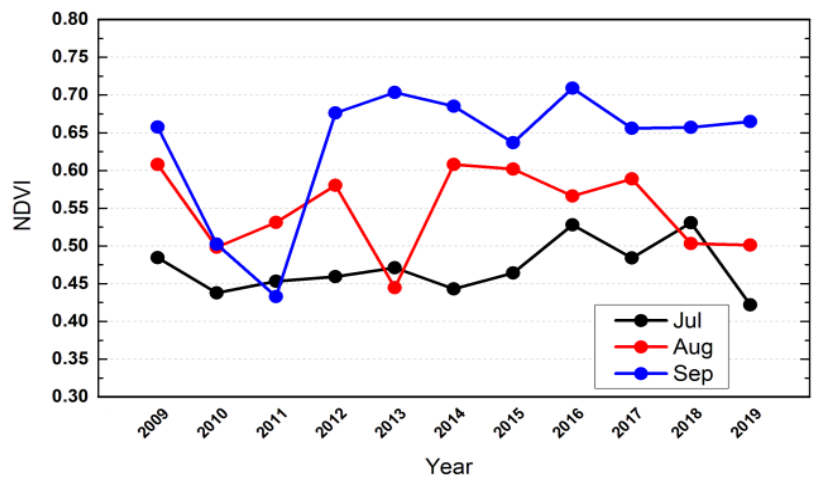

Fig. 2. NDVI analysis results.

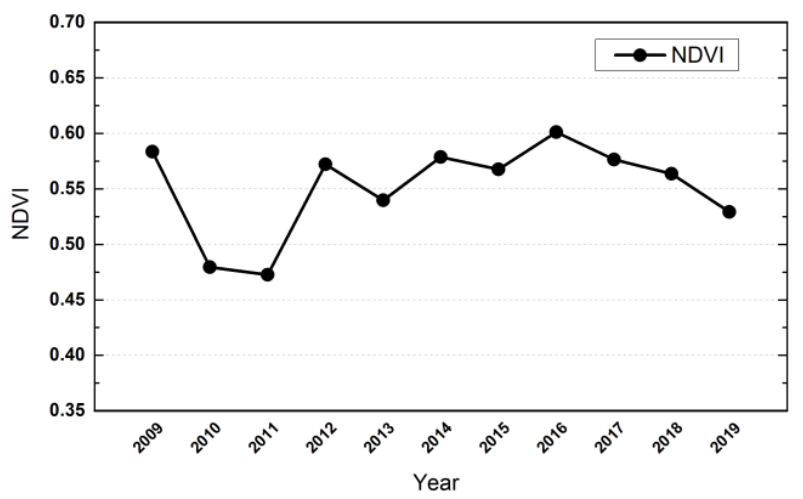

Fig. 3. NDVI analysis average over three months.

\subsection{VCI analysis results}

Three months of different VCI analyses in July showed different plant conditions in the $0-100$ range, which were theoretical values, with the average indicating vegetation conditions or drought for each year. The average was 53.99 the lowest was 38.46 in 2019, and the highest was 70.31 in 2016 .

The August VCI results showed different plant conditions in the $0-100$ range, with the mean value of 60.41 the lowest value of 42.56 in 2013, and the maximum value of 77.01 in 2014 . The results of the September VCI calculation showed different plant conditions in the $0-100$ range, with the average being 67.50 the lowest was 30.59 in 2011, and the highest was 78.83 in 2013.

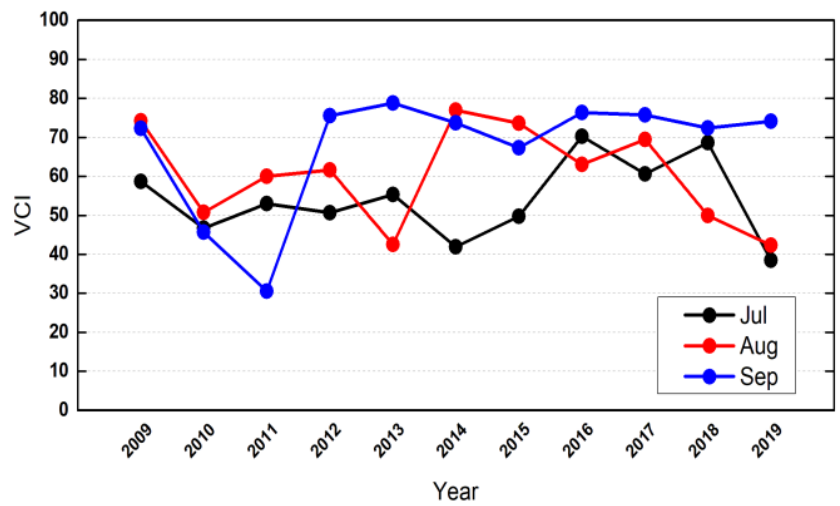

Fig. 4. VCI analysis results. 
The average VCI analysis for all three months throughout the 11 years is shown in Fig. 4 the curve shows the VCI variance for each year with the lowest in 2010 at 47.70 the highest in 2009 at 68.41 and the 11-year average was 60.63 (Fig. 5)

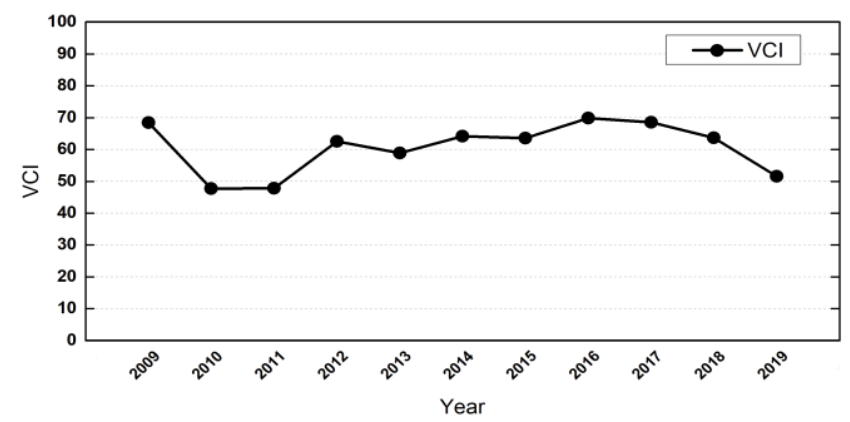

Fig. 5. NDVI analysis average over three months.

\subsection{VCI drought classification results}

VCI analysis can be inferred from the maximum, minimum, mean, and standard deviation of VCI for July, August, and September (2009-2019), with each period revealing different plant conditions. The results of the VCI analysis determined the condition of plants or annual droughts. VCI drought classification for each three-month period over the 11 years is shown in Figs. 6a, b, and c.

Fig. 6a shows that the drought was most severe in 2019 , accounting for $70.82 \%$ of the area or $22,250.31 \mathrm{~km}^{2}$ (the very high level of drought was $12.61 \%$ or $3,961.18 \mathrm{~km}^{2}$, high-level drought was $29.51 \%$ or $36.9,271 \mathrm{~km}^{2}$, moderate-level drought was $28.70 \%$ or $77.9,017 \mathrm{~km}^{2}$ ).
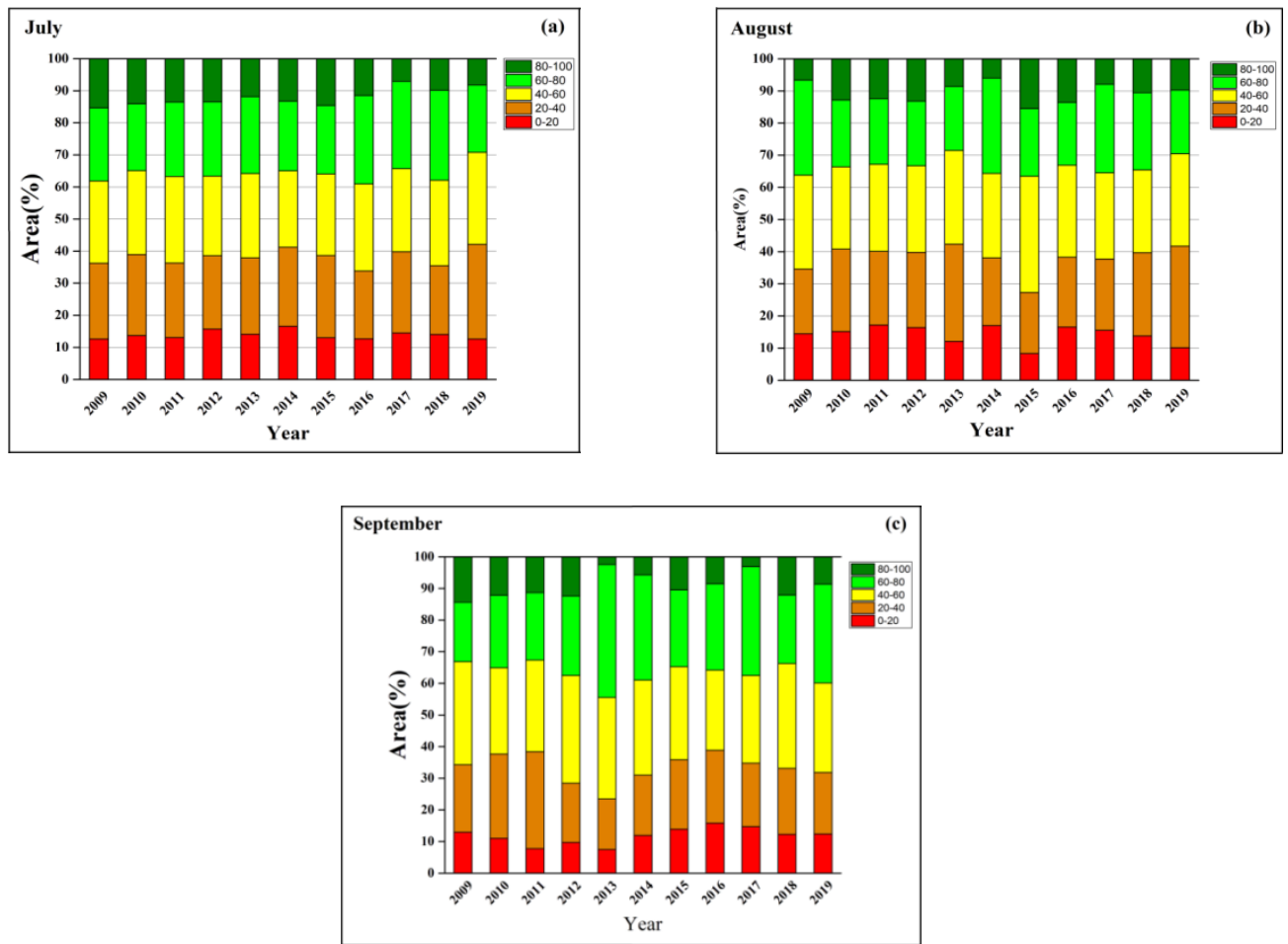

Fig. 6a, b, and c: Three-month VCI drought classification. 
In 2016, the drought covered a minimum of $60.93 \%$ of the area or $19,147.29 \mathrm{~km}^{2}$ (very high-level drought covered $12.66 \%$ or $3,978.47 \mathrm{~km}^{2}$, high-level drought covered $21.16 \%$ or $42.6,649 \mathrm{~km}^{2}$, moderate drought covered $27.11 \%$ or $40.8,519 \mathrm{~km}^{2}$ ).

Fig. 6b displays the August VCI drought classification results, which were classified by the VCI level each year. The results show that in 2013, the drought was most severe, accounting for $71.47 \%$ of the area or $22,456.76 \mathrm{~km}^{2}$ (very high-level drought was $12.11 \%$ or $3,805.64 \mathrm{~km}^{2}$, high-level drought was $30.21 \%$ or $9,493.20 \mathrm{~km}^{2}$, moderate drought levels were $29.14 \%$ or $9,157.92 \mathrm{~km}^{2}$ ).In 2015 , the least drought covered $63.45 \%$ of the area or $19,938.21 \mathrm{~km}^{2}$ (very high-level drought covered $8.29 \%$ of the area or $2,603.40 \mathrm{~km}^{2}$, high-level drought covered $19.03 \%$ or $5,980.74 \mathrm{~km}^{2}$, moderate drought covered $36.13 \%$ or $11,354.07 \mathrm{~km}^{2}$ ).

Fig. 6c shows the September VCI drought classification results with the most drought in 2011, accounting for $67.33 \%$ of the area or $21,157.42 \mathrm{~km}^{2}$ (very high-level drought covered $7.73 \%$ or $2,430.25 \mathrm{~km}^{2}$, high-level drought covered $30.68 \%$ or $9,641.20 \mathrm{~km}^{2}$, moderate drought covered $28.92 \%$ or $9,085.96 \mathrm{~km}^{2}$ ) . In 2013 , drought covered a minimum of $55.55 \%$ of the area or $17,456.42$ $\mathrm{km}^{2}$ (very high-levels drought covered $7.47 \%$ or $2,347.30 \mathrm{~km}^{2}$, high-level drought covered $15.96 \%$ or $5,015.74 \mathrm{~km}^{2}$, moderate drought covered $32.12 \%$ or $10,093.38 \mathrm{~km}^{2}$ ).

To get a clearer picture of the drought, we analyzed drought levels and classified them spatially with the VCI for July, August, and September for the entire 11 years. The results of this spatial VCI analysis are shown in Figs. 7, 8, and 9.

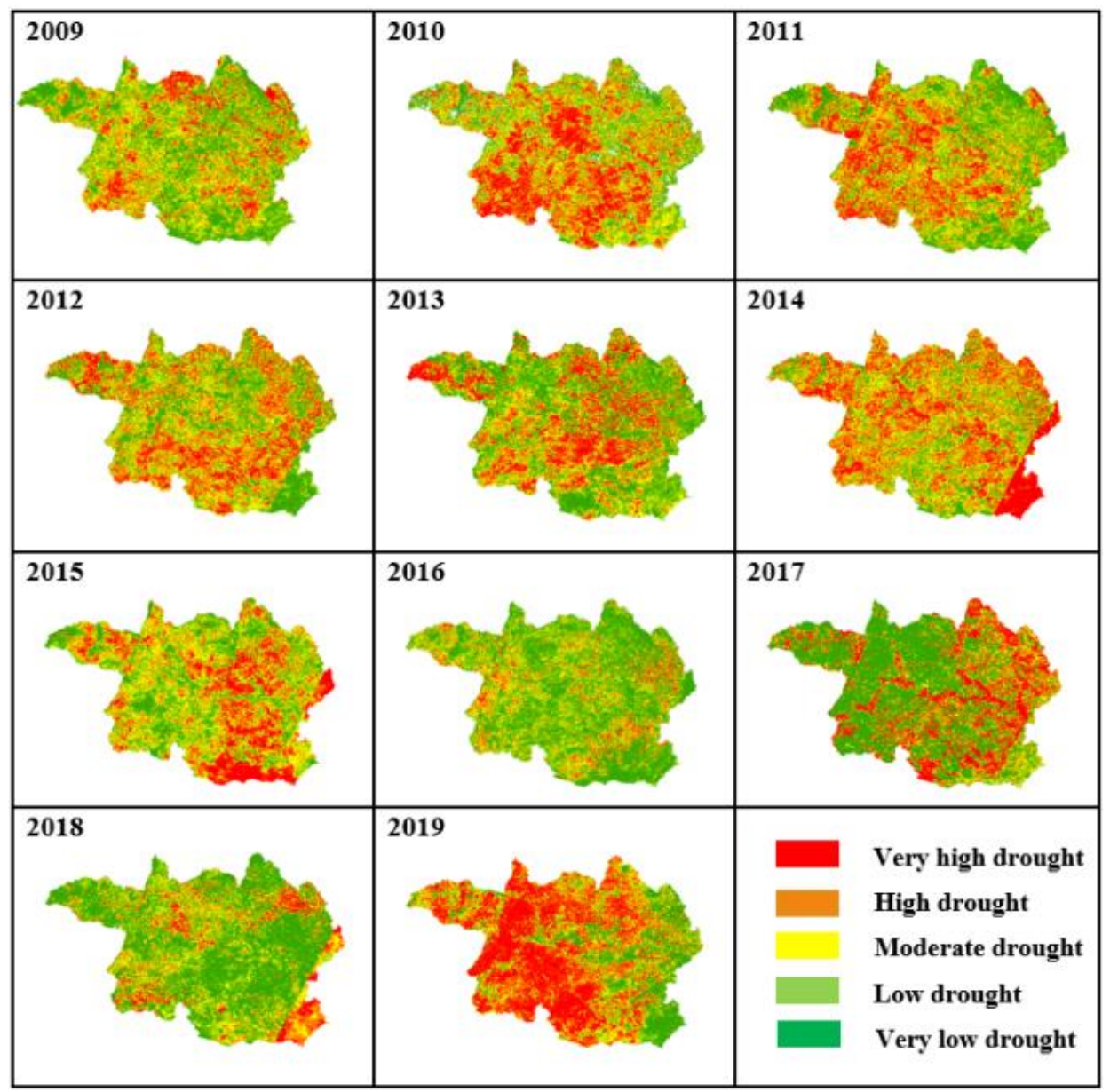

Fig. 7. Spatial analysis of VCI in July. 


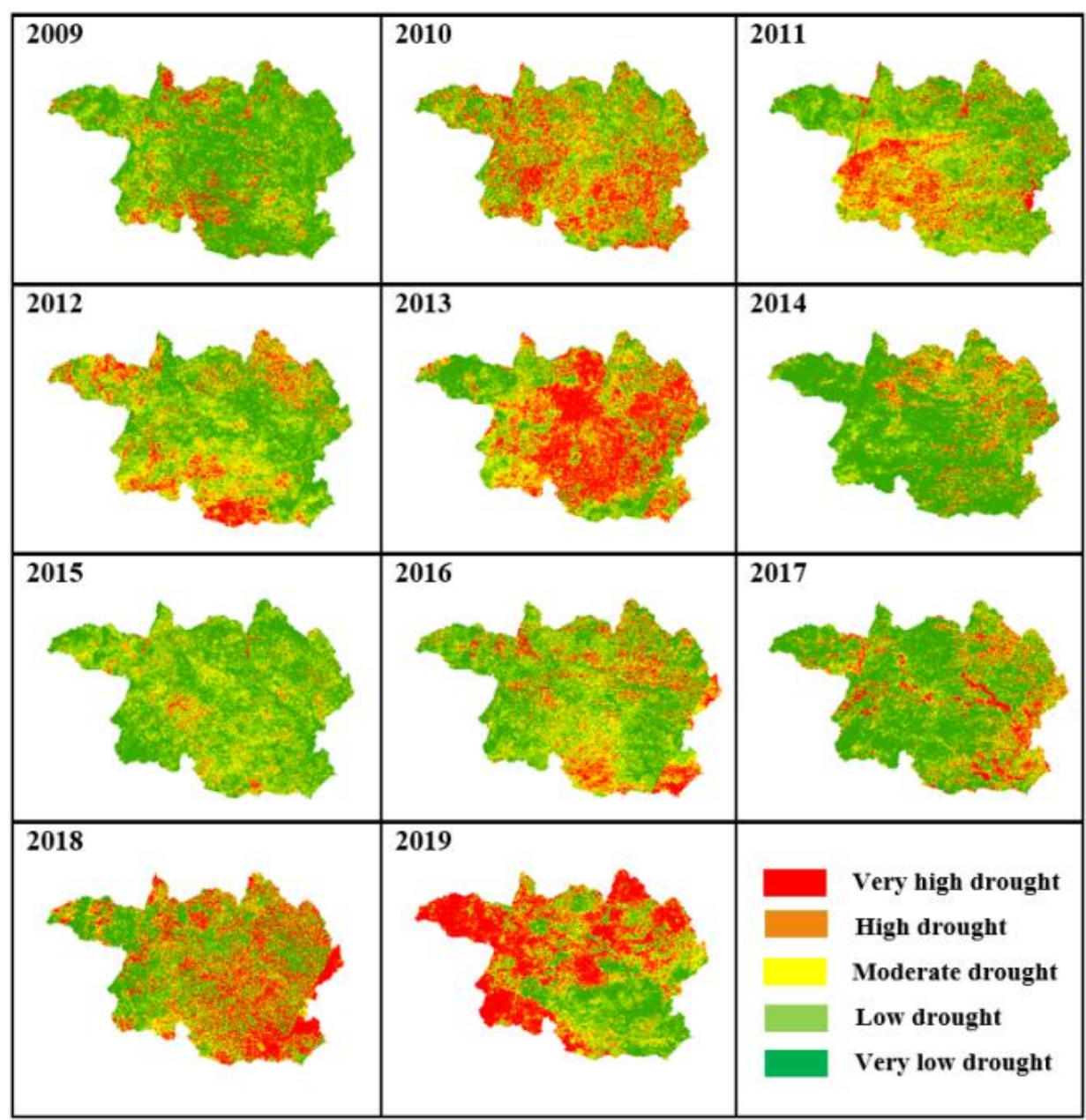

Fig. 8. Spatial analysis of VCI in August.

Figs. 7 to 9 show five drought levels that were classified according to the VCI criteria. These five levels of drought are consistent with Fig. 4 in terms of the maximum drought and minimum drought in each month of the year. In Figs .7 to 9, the yellow, orange, and red areas indicate those that experience much drought. The light and dark green areas indicate those with less drought.

\subsection{Statistical correlation results}

A statistical correlation analysis was performed using linear regression analysis from the monthly mean of the VCI for the three months of the 11 years studied. Results showed that the VCI and rainfall from ground monitoring stations were related, and this is demonstrated in Figs. 8 to 10 . In Figs .10 to 12, there was a high statistical correlation, and the decision coefficients for all three months in the 11 years were $R^{2}=0.835, R^{2}=0.834$, and $R^{2}=0.849$, respectively. 


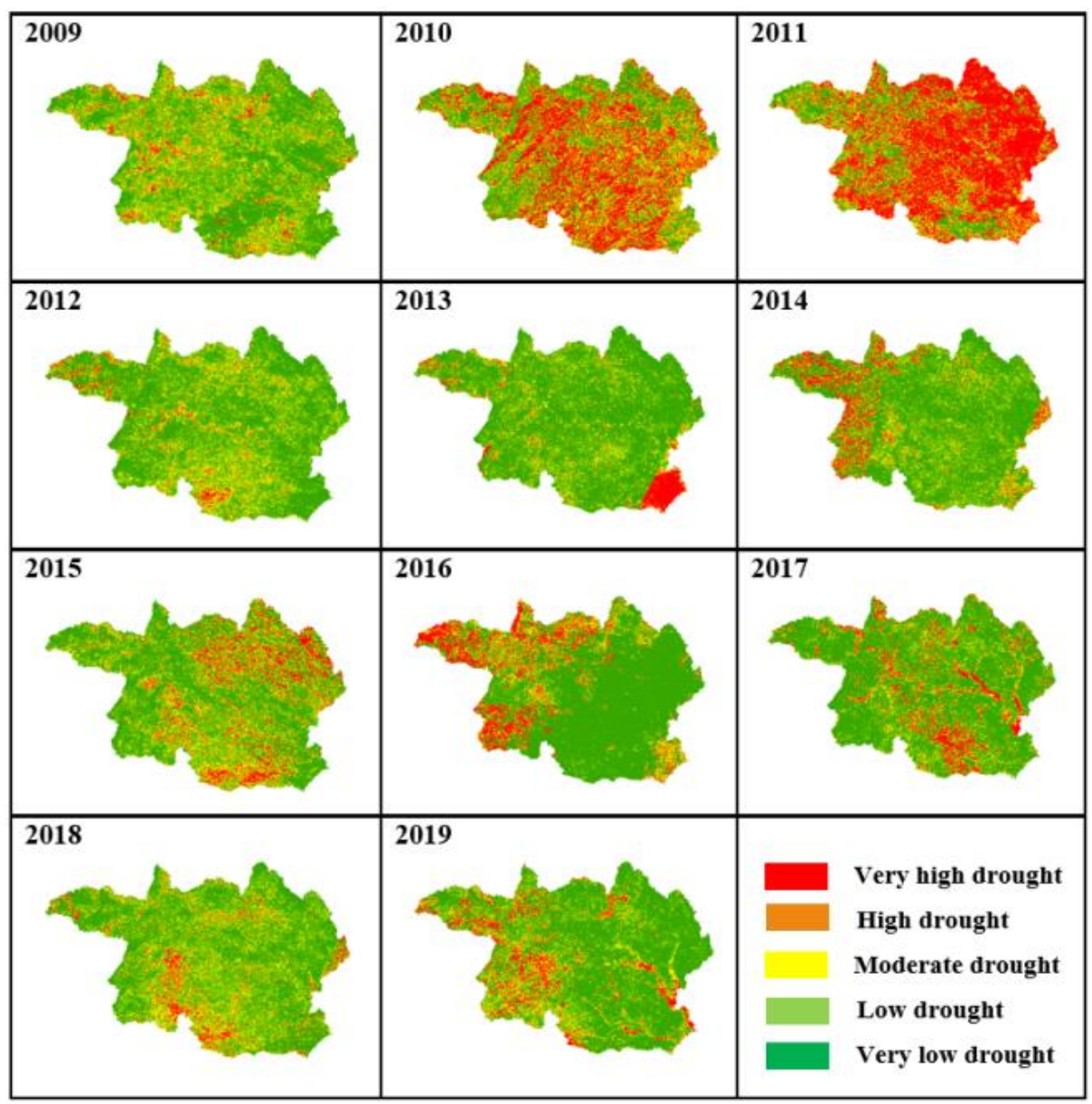

Fig. 9. Spatial analysis of VCI in September.

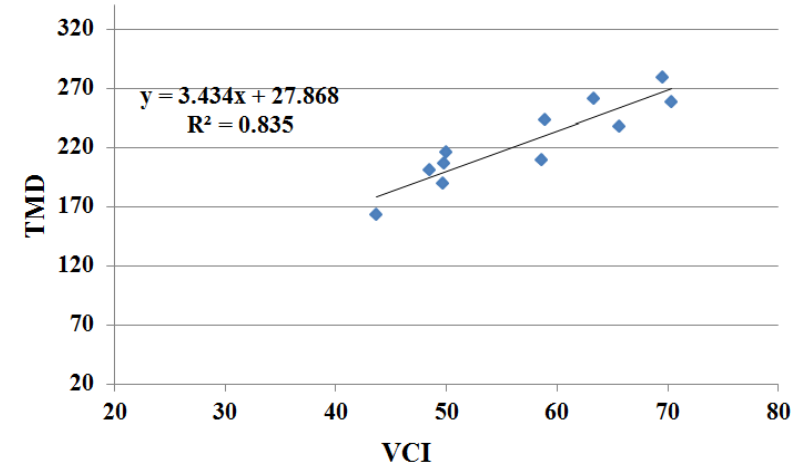

Fig. 10. Relationship between the VCI and rainfall statistics in July. 


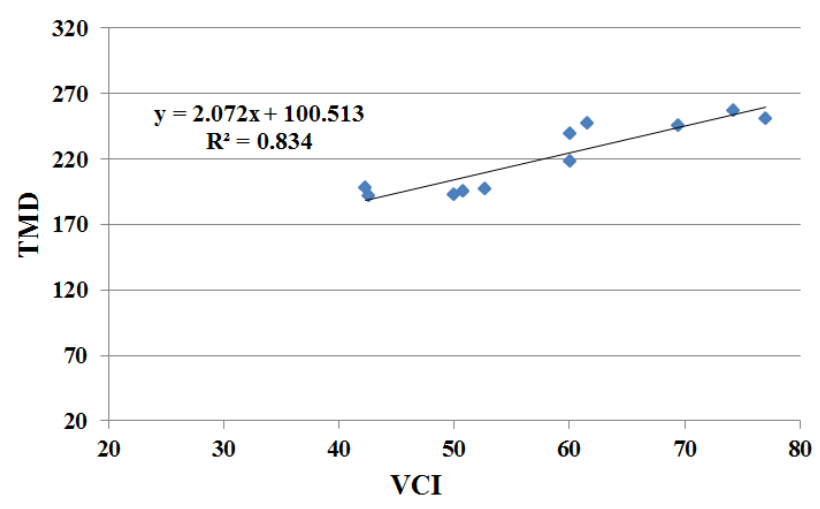

Fig. 11. Relationship between the VCI and rainfall statistics in August.

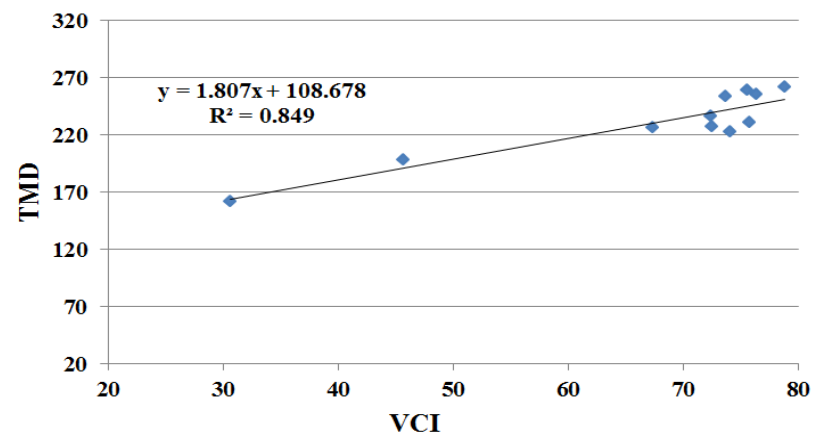

Fig. 12. Relationship between the VCI and rainfall statistics in September.

\section{CONCLUSIONS}

During the past decade, the most severe natural disasters in Thailand have been drought caused by less rainfall than usual or longer seasonal rain that covers a wide area .On the one hand, analyzing the VCI in this study demonstrated that the closer the VCI is to 0 , the greater the area lacks moisture, and drought is very severe .On the other hand, if the VCI was closer to 100 , the area had plenty of moisture, and there was less drought. Furthermore, when there was a high level of rainfall, the VCI was high, but if the rainfall level was low, the VCI was also low. Changes in VCI may be slightly slower than rainfall because vegetation grows and produces green leaves after sufficient water. Additionally, the results of this study aligned with those of three similar studies by Jiao et al. (2016) , Zambrano et al. (2016), and Rousta et al. (2020). The methods and results of this study should serve as criteria for a rational examination of vegetative drought in the northeastern region of Thailand. It is also possible to perform a quick and reliable inspection and assessment of the drought area. Both governmental and non-governmental agencies can apply the methods of this study to analyze expected drought areas and use the results to formulate sustainable drought prevention and mitigation plans in other areas of Thailand.

\section{ACKNOWLEDGMENTS}

This research was financially supported by Mahasarakham University (grant year 2021). 


\section{REFERENCES}

Fensham, R., \& Holman, J. (1999). Temporal and spatial patterns in drought-related tree dieback in Australian savanna. Journal of Applied Ecology, 36(6), 1035-1050.

Furtuna, P. \& Holobaca, I. (2013). Forest fires study using remote sensing and meteorological indicators. Case study. Geographia Technica, 8(2), 23-37.

Gao, B.C. (1996). NDWI - A normalized difference water index for remote sensing of vegetation liquid water from space. Remote Sensing of Environment, 58, 257-266.

Gebrehiwot, T., Veen, A. V., \& Maathuis, B. (2011). Spatial and temporal assessment of drought in the Northern highlands of Ethiopia. International Journal of Applied Earth Observation and Geoinformation, 13(3), 309-321.

Gu, Y., Brown, J.F., Verdin, J. P. \& Wardlow, B. (2007). A five-year analysis of MODIS NDVI and NDWI for grassland drought assessment over the central Great Plains of the United States. Geophysical Research Letters, 34(6), 1-6

Huete, A.R. (1988). A Soil-adjusted Vegetation Index (SAVI). Remote Sensing of Environment, 25(3), $295-309$.

Huete, A., Didan, K., Miura, T., Rodriguez, E.P., Gao, X., \& Ferreira, L.G. (2002). Overview of the radiometric and biophysical performance of the MODIS vegetation indices. Remote Sensing of Environment, 83(1), 195213.

Jiao, W., Zhang, L., Chang, Q., Fu, D., Cen, Y., \& Tong, Q. (2016). Evaluating an enhanced vegetation condition index (VCI) based on VIUPD for drought monitoring in the continental United States. Remote Sensing, 8(3), 224

Jingyong, Z., Wenjie, D.,Congbin, F.,Lingyun, W. (2003). The influence of vegetation cover on summer precipitation in China: A statistical analysis of NDVI and climate data. Adv. Atmos. Sci., 20, 1002-1006.

Kogan, F.N. (1995). Application of Vegetation Index and Brightness Temperature for Drought Detection. Advances in Space Research, 15(11), 91-100.

Kogan, F.N.(1997). Global drought watch from space .Bulletin of the American Meteorological Society, 78, $621-636$.

Laosuwan, T., Sangpradid, S., Gomasathit, T., \& Rotjanakusol, T. (2016). Application of Remote Sensing Technology for Drought Monitoring in Mahasarakham Province, Thailand. International Journal of Geoinformatics, 12(3), 17-25.

Lines, D., Werner, M., \& Bastiaanssen, W. (2017). The predictability of reported drought events and impacts in the Ebro Basin using six different remote sensing data sets. Hydrol. Earth Syst. Sci., 21, 4747-4765.

Malo, A. \& Nicholson, S. E. (1990). A Study of Rainfall and Vegetation Dynamics in the African Sahel Using Normalized Difference Vegetation Index. Journal of Arid Environments, 19, 1-24.

Peters, J.A., Walter-Shea, E.A., Ji, L., Andres, V., Michael, H., Svoboda, M.D. (2002). Drought Monitoring with NDVI Based Standardized Vegetation Index. Photogrammetric Engineering \& Remote Sensing, 68(1), 71-75.

Pettorelli, N., Vik, J.O., Mysterud, A., Gaillard, J.M., Tucker, C.J., Stenseth, N.C. (2005). Using the satellitederived NDVI to assess ecological responses to environmental change. Trends Ecol. Evol., 20, 503-510.

Prohmdirek, T., Chunpang, P \& Laosuwan, T. (2020). The relationship between normalized difference vegetation index and canopy temperature that affects the urban heat island phenomenon. Geographia Technica, $15(2), 222-234$.

Quiring, S .M., and S .Ganesh) . (2010). Evaluating the utility of the Vegetation Condition Index (VCI) for monitoring meteorological drought in Texas, Agric.For.Meteorol., 150 (3), 330-339 .

Rotjanakusol, T. \& Laosuwan, T. (2018). Remote Sensing Based Drought Monitoring In The MiddlePart of Northeast Region of Thailand. Studia Universitatis Vasile Goldis Arad, Seria Stiintele Vietii, 28(1), 14-21.

Rotjanakusol, T., \& Laosuwan, T. (2019a). Drought Evaluation with NDVI-Based Standardized Vegetation Index in Lower Northeastern Region of Thailand. Geographia Technica, 14(1), 118-130.

Rotjanakusol, T., \& Laosuwan, T. (2019b). An Investigation of Drought around Chi Watershed during Ten-Year Period Using Terra/Modis Data. Geographia Technica, 14(2), 74-83.

Rousta, I., Olafsson, H., Moniruzzaman, M., Zhang, H., Liou, Y.-A., Mushore, T. D., \& Gupta, A. (2020). Impacts of drought on vegetation assessed by vegetation indices and meteorological factors in Afghanistan. Remote Sensing, 12(15), 2433. 
Uttaruk, Y., \& Laosuwan, T. (2017). Drought Detection by Application of Remote Sensing Technology and Vegetation Phenology. Journal of Ecological Engineering, 18(6), 115-121.

Uttaruk, Y., \& Laosuwan, T. (2019). Drought Analysis Using Satellite-Based Data and Spectral Index in Upper Northeastern Thailand. Pol. J. Environ. Stud. 28(6), 1-8.

Tarpley, J.D., Schneider, S.R., \& Money, R.L. (1984). Global vegetation indices from the NOAA-7 meteorological satellite. Journal of Climate and Applied Meteorology, 23, 491-494.

Tucker, C.J. (1979). Red and photographic infrared linear combinations for monitoring vegetation. Remote Sensing of Environment, 8(2), 127-150.

Zambrano, F., Lillo-Saavedra, M., Verbist, K., \& Lagos, O. (2016). Sixteen years of agricultural drought assessment of the BioBío region in Chile using a $250 \mathrm{~m}$ resolution vegetation condition index (VCI). Remote Sensing, 8(6), 530.

Zhang, Y., Peng, C., Li, W., Fang, X., Zhang, T., Zhu, Q., Chen, H. \& Zhao, P. (2013). Monitoring and estimating drought-induced impacts on forest structure, growth, function, and ecosystem services using remote-sensing data: Recent progress and future challenges. Environmental Reviews, 21, 103-115. 